\title{
CONTINUITY AND APPROXIMATE DIFFERENTIABILITY OF MULTISUBLINEAR FRACTIONAL MAXIMAL FUNCTIONS
}

\author{
FENG LIU
}

Abstract. In this note we investigate the continuity and approximate differentiability of the $m$ sublinear fractional maximal operator

$$
\mathfrak{M}_{\alpha}(\vec{f})(x)=\sup _{r>0}|B(x, r)|^{\alpha / d-m} \prod_{i=1}^{m} \int_{B(x, r)}\left|f_{i}(y)\right| d y,
$$

where $m \geqslant 1,0 \leqslant \alpha<m d$ and $\vec{f}=\left(f_{1}, \ldots, f_{m}\right)$ with each $f_{j} \in L_{\text {loc }}^{1}\left(\mathbb{R}^{d}\right)$. More precisely, we prove that $\mathfrak{M}_{\alpha}$ maps $W^{1, p_{1}}\left(\mathbb{R}^{d}\right) \times \cdots \times W^{1, p_{m}}\left(\mathbb{R}^{d}\right)$ into $W^{1, q}\left(\mathbb{R}^{d}\right)$ continuously, provided that $1<p_{1}, \ldots, p_{m}<\infty$ and $0<\sum_{i=1}^{m} 1 / p_{i}-\alpha / d=1 / q \leqslant 1$. We also show that the multisublinear fractional maximal functions $\mathfrak{M}_{\alpha}(\vec{f})$ are approximately differentiable a.e. if $\vec{f}=\left(f_{1}, f_{2}, \ldots, f_{m}\right)$ with each $f_{j} \in L^{1}\left(\mathbb{R}^{d}\right)$ being approximately differentiable a.e. As applications, the corresponding results for fractional maximal operators are established.

Mathematics subject classification (2010): 42B25, 46E35.

Keywords and phrases: Multisublinear fractional maximal operator, Sobolev space, continuity, approximate differentiability.

\section{REFERENCES}

[1] D. R. Adams, A note on Riesz potentials, Duke Math. J., 42, (1975), 765-778.

[2] D. R. Adams And L. I. Hedberg, Function Spaces and Potential Theory, Springer-Verlag, Berlin Heidelberg, 1996.

[3] J. M. Aldaz, L. Colzani And J. PÉrez LÁZARo, Optimal bounds on the modulus of continuity of the uncentered Hardy-Littlewood maximal function, J. Geom. Anal., 22, 1 (2012), 132-167.

[4] J. M. AldAZ AND J. PÉREZ LÁZARO, Functions of bounded variation, the derivative of the one dimensional maximal function, and applications to inequalities, Trans. Amer. Math. Soc., 359, 5 (2007), $2443-2461$.

[5] J. M. Aldaz And J. PÉrez LÁZARo, Boundedness and unboundedness results for some maximal operators on functions of bounded variation, J. Math. Anal. Appl., 337, 1 (2008), 130-143.

[6] J. M. AldAZ And J. PÉREZ LÁZARO, Regularity of the Hardy-Littlewood maximal operator on block decreasing functions, Studia Math., 194, (2009), 253-277.

[7] F. J. Almgren And E. H. Lieb, Symmetric decreasing rearrangement is sometimes continuous, J. Amer. Math. Soc., 2, (1989), 683-773.

[8] M. CAO AND Q. XUE, Characterization of two-weighted inequalities for multilinear fractional maxiaml operator, Non. Anal. TMA, 130, (2016), 214-228.

[9] M. CAO AND Q. XUE, Two-weight entropy boundedness of multilinear fractional type operators, J. Math. Inequa., 11, 2 (2017), 441-453.

[10] E. CARneIRo AND J. MADRID, Derivative bounds for fractional maximal functions, Trans. Amer. Math. Soc., to appear.

[11] E. Carneiro And D. Moreira, On the regularity of maximal operators, Proc. Amer. Math. Soc., 136, 12 (2008), 4395-4404.

[12] E. CARNEIRO AND B.F. Svaiter, On the variation of maximal operators of convolution type, J. Funct. Anal., 265, (2013), 837-865. 
[13] P. HajŁasz and J. Maly, On approximate differentiability of the maximal function, Proc. Amer. Math. Soc., 138, 1 (2010), 165-174.

[14] P. HajŁasZ And J. OnNinen, On boundedness of maximal functions in Sobolev spaces, Ann. Acad. Sci. Fenn. Math., 29, 1 (2004), 167-176.

[15] J. Kinnunen, The Hardy-Littlewood maximal function of a Sobolev function, Israel J. Math., 100, (1997), 117-124.

[16] J. KinnUnen And P. LindQvist, The derivative of the maximal function, J. Reine. Angew. Math., 503, (1998), 161-167.

[17] J. Kinnunen And E. SaKsman, Regularity of the fractional maximal function, Bull. London Math. Soc., 35, 4 (2003), 529-535.

[18] O. KuRKA, On the variation of the Hardy-Littlewood maximal function, Ann. Acad. Sci. Fenn. Math., 40, (2015), 109-133.

[19] A. K. Lerner, S. Ombrosi, C. Pérez, R. H. Torres and R. Trujillo-González, New maximal functions and multiple weightes for the multilinear Calderón-Zygmund theory, Adv. Math., 220, (2009), 1222-1264.

[20] K. LI, K. Mone AND W. SUN, Sharp weighted inequalities for multilinear fractional maximal operator and fractional integrals, Math. Nachr., 288, (5-6) (2015), 619-632.

[21] K. LI AND W. SUN, Characterization of a two weight inequality for multilinear fractional maximal operators, Houston J. Math., 42, 3 (2016), 977-990.

[22] F. LiU, A remark on the regularity of the discrete maximal operator, Bull. Austral. Math. Soc., 95, (2017), 108-120.

[23] F. LiU, T. Chen AND H. Wu, A note on the endpoint regularity of the Hardy-Littlewood maximal functions, Bull. Austral. Math. Soc., 94, (2016), 121-130.

[24] F. LiU AND S. MAO, On the regularity of the one-sided Hardy-Littlewood maximal functions, Czech. Math. J., 67, 142 (2017), 219-234.

[25] F. LiU AND H. Wu, On the regularity of the multisublinear maximal functions, Canad. Math. Bull., 58, 4 (2015), 808-817.

[26] F. LIU AND H. WU, Endpoint regularity of multisublinear fractional maximal functions, Canad. Math. Bull., to appear. DOI:10.4153/CMB-2016-044-9.

[27] F. LiU AND H. WU, Regularity of discrete multisublinear fractional maximal functions, Sci. China Math., to appear. DOI:10.1007/s11425-016-9011-2.

[28] F. LIU AND H. WU, On the regularity of maximal operators supported by submanifolds, J. Math. Anal. Appl., 453, (2017), 144-158.

[29] H. LuIRO, Continuity of the maixmal operator in Sobolev spaces, Proc. Amer. Math. Soc., 135, 1 (2007), 243-251.

[30] H. LuIRO, On the regularity of the Hardy-Littlewood maximal operator on subdomains of $\mathbb{R}^{n}$, Proc. Edinburgh Math. Soc., 53, 1 (2010), 211-237.

[31] H. Luiro And J. NuUtinen, On the continuity of discrete maximal operators in Sobolev spaces, Ann. Acad. Sci. Fenn. Math., 39, (2014), 175-185.

[32] B. MucKenhoupt AND R. L. WheEdEn, Weighted norm inequalities for fractional integrals, Trans. Amer. Math. Soc., 192, (1974), 261-274.

[33] C. PÉRez And R. WheEden, Potential operators, maximal functions, and generalizations of $A_{\infty}$, Poten. Anal., 19, 1 (2003), 1-33.

[34] H. TANAKA, A remark on the derivative of the one-dimensional Hardy-Littlewood maximal function, Bull. Austr. Math. Soc., 65, 2 (2002), 253-258.

[35] H. Whitney, On totally differentiable and smooth functions, Pacific. J. Math., 1, (1951), 143-159. 